I acknowledge that this paper is NOT the published version. It is the author's final and peerreviewed manuscript. You may get the published version here: International Journal of Applied Philosophy, Vol. 33, No. 2 (2019): 187-202. DOI: 10.5840/ijap2020227123.

I acknowledge that this version of the paper does not violate the copyright to the International Journal of Applied Philosophy. I also acknowledge that rights and permissions are managed by the Philosophy Documentation Center. No one can copy/distribute or host elsewhere this article without the express permission from the Philosophy Documentation Center.

\title{
The Motivation Problem, Future Generations, and the Idea of "Leaving the Earth No Worse"
}

\begin{abstract}
The author examines the problem of motivation about future generations. He argues that though many philosophers think that direct motivations are problematic for future generations only, they are not unproblematic for the current generations too, and that the motivation problem can be solved if we consider the idea of "leaving the earth no worse." He also shows why such an idea should be promoted and can motivate us to work in the best interests of current and future generations. The author also contends that prioritizing the idea of "leaving the earth no worse" is not exclusively anthropocentric.
\end{abstract}

\section{Introduction}

As the continuing existence of human beings is threatened by numerous catastrophic events, moral issues regarding future generations come to the fore. It may well be that those of us in currently existing generations bear responsibility for the harm our actions may cause to these future generations. But some philosophers are skeptical that such abstract considerations as the potential 
harm that might be done to hypothetical not-yet-born humans can motivate us to act responsibly.

This issue is known as the problem of motivation. The aim of this paper is to closely examine this problem by making the following two claims: a) the direct motivations to care for both present and future generations are challenging, and b) the motivation problem can be solved if we consider the idea of "leaving the earth no worse," which is a novel proposal.

To facilitate the purpose, I divide the paper into six sections. In the first three sections, I delineate the four conditions of being morally responsible following Partridge 1 , the motivation problem raised by $\mathrm{Care} 2$, and the direct and indirect motivations to care for future generations, respectively. Then, I discuss Passmore's idea of "chain of love” from which I derive an original account to solve the motivation problem, namely, the idea of "leaving the earth no worse." In the following section, I show why we should care for future generations in order to make explicit the advantages of the idea of "leaving the earth no worse." The last section provides a discussion on the inverse relationship between environmental degradation and the idea of "leaving the earth no worse" though my proposal is a version of weak anthropocentrism.

\section{Moral Responsibility}

Why should we care for future generations? There are many objections raised against the position that current people have moral responsibilities to future people. Prominent among them is the problem of motivation, which is the main focus of this paper. Before delving into that discussion, it is critical to be aware of the following background study.

The issue of moral responsibility is impregnated with various complications related to epistemology, psychology, ethics, etc. Its complications grew to a new height when current people's responsibilities to future people came to the fore in the 1970s and 1980s. I confine this 
discussion only to Ernest Partridgez who made a significant contribution to future generations literature.

When we say that an agent has a moral responsibility or duty or obligation 4 for his actions, we entail that the agent: "(a) has, or is capable of having, knowledge of the consequences of those actions; (b) has the capacity to bring about these actions; (c) has the choice to do otherwise; and (d) that these consequences have value significance."5 By value significance6, Partridge means "either that the act best exemplifies respect for the rights of affected beings ('deontological value') or that the act optimally affects the welfare of beings with interests - that is, beings who can be benefited or harmed ('teleological value')."7 Thus, according to Partridge, moral responsibility entails the fulfillment of four conditions: (a) knowledge, (b) capacity, (c) choice, and (d) value/moral significance.

Considering moral responsibility from this perspective, it is often inferred that future generations should not be factored into the scope of our moral obligations. But it is not completely true. The posterity problem becomes clear, more than ever, in the dawn of the twenty-first century. It is an age of science (knowledge) and technology (capacity). Due to the extraordinary expansion of scientific knowledge, we now know, for example, that large scale application and development of nuclear energy results in the production of extremely poisonous radioactive materials that have the potential to harm nature's biodiversity for years to come. Hence, current generations have the capacity to affect the well-being of future generations through their actions. Additionally, we are now living in an age of information sciences which augment our capacity to predict with confidence the long-term consequences of present actions. In light of recent developments and technological innovations, the same argument relieving current individuals from neglecting their moral obligations towards future generations due to a lack of knowledge and capacity (two 
conditions of moral responsibility) does not hold ground. Due to astonishing advances in science and technology, we have knowledge and capacity of calculating the consequences of any of our policies and actions to which future generations are vulnerable and taking alternative measures thereby. Thus, it is said,

Where previously we did not have to consider our moral obligations to future generations because two of the four criteria of moral responsibility - capacity and knowledge - could not be met, by the mid-twentieth century moral agents in Western society suddenly fulfilled all four, and in doing so became obligated to an entirely new class of moral patients: those living in the remote future. 8

However, problems related to the choice criterion of moral responsibility towards posterity persist. It is true that we can be aware of the consequences that our actions and policies would inflict on future generations. It is also true that we have the capacity to bring about these actions and policies. But why do we choose to care for future people? What motivates us to choose to care for them? Similar questions arise in connection with the capacity condition of moral responsibility since capacity encapsulates both psychological and technological effects. 9 As a result, two criteria of moral responsibility - capacity and choice - lead to a very annoying problem known as the problem of motivation, for which the next section is allocated.

\section{The Problem of Motivation}

Dieter Birnbacher10 shows that the motivation problem has a long tradition in moral philosophy, and becomes very stringent when the issue of distant future arises. He discusses universalistic, particularistic, and communitarian positions in this connection. He hypothesizes that the maxim of non-harming can be applied to potential "moral patients" of both current and future times. He refers to such universalists as Henry Sidgwick and Immanuel Kant - both of whom believe that 
the temporal position of the person harmed by a current action is not pertinent to its moral evaluation. Similarly, some variants of particularistic, or communitarian morality, according to Birnbacher, are consistent with universalistic systems regarding temporal universalization. The key differences between them are about ethnic, social, and cultural boundaries.

However, this last point poses a serious problem for the universalists. They cannot deal with the psychological gap, which is a result of different ethnicities, societies, and cultures. According to Birnbacher, moral emotions such as love of humanity, a sense of justice and international solidarity, etc. are less powerful indicators of motivation than immediate emotions of egoism, family bonds, group solidarity, and patriotism.11 So, if the motivation problem poses a dilemma for the contemporaries living in distant relations, the consequence is even graver for the temporally distant people.

The problem of motivation is made famous in the context of environmental philosophy by Norman S. Care through his 1982 paper "Future Generations, Public Policy, and the Motivation Problem." Care investigates what motivates people to be responsible for future generations. He evaluates several ways that are given as motivating factors in this regard. In the absence of such conditions of motivation as particularity about persons and reciprocation between persons, the question of the morality of any policies about future generations implemented by current people is not available.

According to Care, present people do not feel love or concern for future people because the latter are faceless and impersonal characters. Because of their nonparticularity, i.e., facelessness and impersonality, future generations do not have the capacity to interest - a precondition or a fundamental part of arousing love or concern - existing generations. Moreover, the interest of future generations is indeterminate, since we do not know what their wants, needs, 
hopes, and fears will be. Since current people do not know about what interests future generations might have, these indeterminate interests fail to motivate present generations to feel love or concern or responsibility for future generations. As Care notes,

If a person were to profess or claim to be moved by love or concern for future people, or even for future people qua interests, I would have to say that something other than the love or concern I have indicated is being referred to, or perhaps that what I earlier called "feeling tones," or characteristic feelings associated with the love or concern I have indicated, were aroused by something else, i.e., something other than future people or future people qua interests, or the idea of either of these. (Perhaps they were aroused by a drug.) 12

Another form of motivation problem identified by Care is what he calls community bonding, which at its minimum level involves "a sense of belonging to some joint enterprise with others." 13 This feeling of belonging as the motivational factor, according to Care, is composed of "the feeling tones of solidarity, comradeship, loyalty, mutual confidence, and trust, or at least a sense of being-on-the-same-side." 14 For any action or event detrimental to the community bonding, the responsible person "may experience guilt, or dismay, or regret. Just as the particularity condition of the motivation problem expressed in the form of love or concern, the problem of motivation expressed in the form of community bonding is labeled by Care as the reciprocation condition. By reciprocation, Care means, "the exchange of ideas and conceptions of purposes that must be available to persons before they can be considered to stand as joint participants in a common project."15

After explaining the reciprocation condition, Care applies it to the case of future people. He argues that either of current and upcoming people cannot reciprocate with one another about 
any enterprise and association. Because of the absence of such reciprocity, present people do not feel motivated for future people in the form of community bonding. So, for future people, present people do not feel solidarity, comradeship, loyalty, mutual confidence, and trust, or being-on-thesame-side. Current people neither experience any feelings of guilt, or dismay, or regret for future people since there is no question of damaging the relationship with the faceless and impersonal future people. Thus, Care argues,

If a person claimed to feel guilt as a result of faults in his or her conduct toward future people, I would have to say that the experience of guilt referred to is of a different kind from that which may be explained by reference to motivation in the form of community bonding. 16

Apart from the motivations of love or concern and community bonding, Care also considers a kind of motivation which is grounded either in particularity about persons or in reciprocation between persons. He calls it extended or unbounded shared-fate motivation. He uses it in the sense of common humanity that "involves at some level the notion that in a very general way human beings as such 'belong together,' or are 'in life together,' irrespective of differences in time and location among them." 17 In other words, the extended or unbounded shared-fate motivation is grounded in "the idea of a community of persons who may be at any temporal or social location, and who nevertheless construe themselves as 'being in life together' or 'sharing fate' according to the contents of an appropriate conception of what morality requires of the members of such a community." 18 According to Care, this idea has no spatial and temporal limits for three reasons: a) "It is an idea of a community in which not all or even very many of the members can reciprocate with each other;" b) "It is an idea of a community in which not all or even very many of the 
members have - in principle - particularity for each other;" c) "It is an idea of a community in which the membership is unbounded in all ordinary ways." 19

Though Care thinks that the extended shared-fate motivation is intelligible as a possible form of motivation among human beings, he shows serious empirical doubt about its availability and reliability. This sort of motivation is beyond our reach or too difficult to develop in the presence of "certain institutional elements in the makeup of our society" and "current received moral ideology."20

Care, therefore, shows pessimism about the present people's obligation to upcoming generations. According to him, the two familiar sorts of motivations - love or concern (grounded in particularity) and community bonding (grounded in reciprocation) - cannot make present generations morally obliged to make a serious sacrifice for future generations. On the other hand, another familiar sort of motivation - extended or unbounded shared-fate (grounded in spatially and temporally infinite community membership) - asks for "an overhaul of main elements in the makeup of our society which influence the moral psychology of citizens" though such motivation wants current people to make serious sacrifice for the sake of future people. 21

However, this conclusion of Care does not entirely end the possibilities for favoring the policies that would ensure a just world for the future world. In the upcoming sections, I focus on such possibilities.

\section{Motivations, and Present and Future Generations}

Human beings have rationalistic, altruistic, and self-interested motives. We can say that an action is done from rationalistic motives if the reason or moral judgment that moves an agent to action is conscientiousness or a feeling of duty. That is, the action is done because it is morally required. The Kantian categorical imperative is an example of such motives. An action is done from altruistic 
motives if it is done out of such altruistic motives as love, care, compassion, empathy, solidarity, generosity, and so forth. Hume labels them as "fellow feelings." 22 The self-interested motives are the motives of reputation, self-respect, personal gain, and the pursuit of individual goals. It is to be noted that any combinations of these motives can also be found. Moreover, each category of motives can be either direct or indirect. "The distinction between direct and indirect motives concerns whether an act is intended to benefit a moral patient directly or is merely the by-product of an action aimed at some other beneficiary." 23 Now, I consider the direct and indirect motives in the context of present and future generations.

Direct rationalistic motives drive current people to work for future people because it is right to act for future people. Partridge 24 recounts two incidents from the former Soviet Union that he borrows from Garrett Hardin25,

In the first, during the 1921 famine, peasants in a starving village on the Volga refused to eat the seed grain stacked in an adjacent field. "We do not steal from the future," they said. In the second case, during the 900-day siege of Leningrad, while nearly a million residents starved, large stores of edible seeds in an agricultural research institute were untouched.

The direct rationalistic motives are too strong to implement. Their strength is their weakness. These motives are expressed in such abstract ways that sometimes it is hard to understand how they work to move people to any action, let alone actions related to future generations. The two extraordinary cases from the former Soviet Union mentioned above are so rare that nowadays environmental philosophers, in general, do not justify our responsibility to future generations on the basis of direct rationalistic motives. 
Direct altruistic motives move current people to act for future people because of the abstract love of humankind. But many philosophers (e.g., Hume) question whether it is possible to feel such abstract love of humanity. Moreover, loving humanity in this way can take the form of "Jellby fallacy." It is a fallacy named after the character Mrs. Jellby in Charles Dickens' Bleak House. Jeremy Waldron describes, "[Mrs. Jellby] is the very image of the cosmopolitan moralist preoccupied with the distant because it can so readily be made abstract, and ignoring the grubby reality of what is going on around her." 26

It seems that the direct altruistic motives might provide stronger motives than the rationalistic motives for working for future generations. But unfortunately, they are not available for the lack of what we may call "intergenerational species." 27 Such altruistic motives as love and sympathy are absent in our dealing with future people - except some of the members of the generations to come including our children, grandchildren, etc. So, future generations mostly remain faceless and invisible to us. As a result, they are objects of our thoughts and calculations. They are objects of our moral consideration only as abstract recipients of goods and potential anonymous victims of harm. Unlike the people who are in front of our eyes, future people cannot activate any moral emotions in us for not being as concrete and experientially accessible objects of attitudes, such as love, friendship, reverence, or solidarity.28

Direct self-interested motives are the sort of motives that cannot be used in the best interests of distant future people. It is argued that the person who works to further his or her interests cannot thereby directly intend to further the benefit of future people, although s/he can do it accidentally.29 Present generations can work for future generations so that the latter erect monuments to commemorate their services. Present people can feel obligations to future individuals in the hope that the latter will re-edit their scholarly works, name buildings, streets, or many discoveries after 
them. But these may not affect efficiently the present people to work in the best interests of future people because the manifestations of them are too symbolic. Few people are mainly driven by the posthumous fame apart from possibly few social and intellectual elites.

So far, I have considered whether direct rationalistic, altruistic, and self-interested motives move present generations to work on behalf of future generations. But if we consider them carefully, we understand that sometimes some of these motives cannot be employed even in the best interests of present people. Consider the direct rationalistic motives. Do we all always move to work for our contemporaries, especially those who live in another part of the globe with whom we have no chance to interact, out of our conscientiousness or a feeling of duty? I do not think the answer is affirmative. If so, the direct rationalistic motives fail not only to move us to be morally responsible to future generations but also fail to motivate us to care for our contemporaries. Doing something out of self-interest is not morally very praiseworthy even in the context of our dealings with the people living around us. So, we are left with only the direct altruistic motives in our moral dealings with both current and future generations. My position in this regard is that for being altruistic, it is not very important to see whether the interactions are direct or indirect. The genuine altruistic consideration should not consider the presence or absence of the people. If I love humankind, if I am very generous, and so forth, then I should not take into account whether the person is from another country, or whether s/he is from my generation or my father's generation, or whether s/he is present now or not. True altruistic attitudes are ones which are done regardless of spatial, temporal, or social distance. Like direct rationalistic and self-interested motives, sometimes direct altruistic motives fail to truly move current people to care for both present and future people. Thus, it is not necessarily true that direct motives are problematic for motivating us 
to care for future people. Sometimes they face problems to motivate us even to care for the people who live at the same time as ours.

From our discussion about direct motivations, it seems that the direct motivations for our actions with respect to future people do not necessarily always remain present because of the remoteness condition that prevents us from the adequate response to the needs of future generations. I think one good way to circumvent such conditions is to see certain good or value as a by-product in the intergenerational context. In this connection, the idea of indirect motivations can make excellent sense. As mentioned, the indirect motives are motives that drive a moral agent to do good to a moral patient as the by-product benefit of an action that is aimed at some other beneficiary. The by-product benefit can be accidental as well.

However, for the same sort of fuzziness discussed in relation to the direct rationalistic motives, I do not delve into the indirect rationalistic motives. Rather, I am going to consider indirect self-interested and altruistic motives.

The indirect motivations aim at producing goods or preventing evils of the present people or the near future people. The appeal to long-term indirect self-interest is not convincing almost for the same reason that I have mentioned above with respect to direct motives. People often tend to sacrifice long-term goal when it is compared with more concrete and immediate self-interest of the present and near future.

But the indirect altruistic motivations have a practical advantage. They harbor a more reliable emotional basis and convey useful potential guidelines about our behavior. Unlike direct altruistic motives, they are supported by a greater number of psychological factors. Even though they are necessarily abstract and impersonal, they are more able to get access to our experience, and by doing so, they produce some by-product benefits for the people of the future. For example, 
the love for my children can play a role in arousing within me the motivation to love my grandchildren, which is an indirect consequence of loving. So, in caring for proximate objects, "the hope is that a person will additionally benefit the object of moral concern, to wit, distant future generations." 30

In the last fifty years, many models of an indirect altruistic motivation aiming at future generations have been proposed. But among them, the most popular construction is John Passmore's idea of "chain of love." The next section is allotted to the critical evaluation of this model. In doing so, I propose a new idea, which is consistent with Passmore31. I believe my proposal has the strength to face the motivation problem.

\section{"Chain of Love" and the Idea of "Leaving the Earth No Worse"}

By "chain of love," Passmore means that the motive of love of each generation for its children and grandchildren can be extended to further generations into the future.32 Passmore says, "Men do not love their grand-children's grand-children. They cannot love what they do not know. But in loving their grandchildren ... they hope that those grand-children, too, will have grand-children to love. They are concerned, to that degree, about their grand-children's grand-children." 33 Since each subsequent generation is in a better position to know what the well-being of upcoming generation will be, each generation will feel motivated to do things that constitute the welfare of the generation coming after one's generation. An excellent short description of the idea of "chain of love" is found in Grove-Fanning, which is as follows,

[Chains] of love, linked together in units of three (parents, children, and grandchildren), run to and through posterity ... [Because] the direct object of motivational concern is restricted to one's grand-children (the third generation) and one's grandchildren, in turn, are directly concerned for their grand-children (the fifth generation), 
the activity of caring for one's immediate [descendants] generates an uninterrupted chain of concern extending indefinitely into the future. Moreover, because the chain of love ultimately relies on a parent's affection for her or his children and grandchildren, a love that is both an innate response and learned behavior..., it is reasonable to think that future generations can be protected. 34

The chain of love can be interpreted and instantiated in several ways. My proposal is to fill it out by the idea of "leaving the earth no worse." By the idea of "leaving the earth no worse," I mean the motivation that one will not unnecessarily take any action that would make the condition of the earth worse than the condition s/he got it from his or her parents. If this concern can be extended to the very next generation, following the "chain of love," then we can have an earth where our grandchildren's grandchildren, and so on, can live a worthy life.

The idea of "leaving the earth no worse" has several important benefits. For the welfare of future people, we do not need to make any unrealistic sacrifices. Parents have natural interests in their children's betterment. If parents, moved by their children's well-being, take no environmentally harmful measures in their own backyard and around (I mean, in their daily life), then at the time of their death, they will leave an earth to their children that is no worse to live than they got from their parents. Hence, the idea of "leaving the earth no worse" can be interpreted as a natural propensity for which no dramatic and unrealistic sacrifices has to be made.

Another prospective advantage of implementing the idea of "leaving the earth no worse" is the fact that it negates the consideration of remote future generations while actively putting the idea to work - this increases the possibility of being moved to work on behalf of future generations. Hence, this idea is more consistent with the partialist account of moral responsibility, according to which, current and near-future generations are morally considerable. In saying so, I also want to 
note that my proposal does not deny that far future generations are not morally considerable. In that regard, to some extent, it is also consistent with the impartialist account of moral responsibility. The idea merely proposes that in our action, we do not need to take the far future generations into our consideration. Any concentration on near-future generations will keep the earth unharmed that will be bequeathed to the next generation. Thus, leaving the earth no worse will indirectly promote the well-being of far future generations, but it will directly promote the welfare of near-future generations. In this way, it will practically be able to motivate current generations to care for the near-future generation to come. Hence, the idea of "leaving the earth no worse" solves the motivation problem. Following this idea will directly motivate current generations to work in the best interests for near-future generation and indirectly for far future generations, while it morally considers both types of future generations. Thus, the idea of "leaving the earth no worse" can be regarded as a proposal that synthesizes impartialist and partialist accounts of moral responsibility.

However, Partridge 35 argues that the idea of "chain linking" is flawed for two reasons:

Firstly, the idea of chain linking implies that "childless individuals are incapable of caring for future generations, and thus are excused from making just provision." 36

Secondly, "Rawls's "heads of families" condition presents a "discounting" problem even more severe than that of the economists, for a parent's love and concern for a child is generally greater than for grandchild, and so on, diminishing to insignificance within a very few generations." 37

But I think the way I propose to instantiate Passmore's “chain of love" idea can cope with these two criticisms as well. While having a child accentuates the possibility of being more receptive to the idea of "leaving the earth no worse," not having a child does not adversely affect 
the implementation of the proposal in place, should one be receptive to it. One can have such concern even if one has neighbors. For instance, even the trivial - although devilish - act of throwing a banana peel onto the pathway of my neighbors can have devastating effects as they, along with random citizens like mailman or delivery personnel crossing that pathway, are at a risk of getting injured. So, I should keep the way at least as clean and unharmed as it was. To properly comprehend the gravity of this situation, one does not necessarily need to harbor another kin with blood ties (i.e., have a child). What I need is to be a social human being. If I throw banana peels here and there, I am morally blameworthy. Similarly, to understand that keeping the earth as it was, we do not need to be a father or mother. What we need to be is a good social human being.

Moreover, the "discounting" problem is not an issue for the idea of "leaving the earth no worse." If each of us has equal concern for keeping the world as it was, then the question of diminishing effect should not arise. In this connection, my proposal is in a better position than the idea of "chain of love." Whereas parents' love for their remote posterity can diminish, their concern for keeping the earth as it was for the very next generation cannot be diminished. Passmore takes three generations (parents, children, and grandchildren) into his consideration, whereas I am only taking the current generation and the generation next into my account. So, my proposal has less risk of being a victim of diminishing effect.

The idea of "leaving the earth no worse" can deal with the motivation problem. We have direct motivations, as I have already discussed, for the persons whom we can meet face-to-face. If we can do that, then no problems related to particularity and reciprocation should arise. Since my proposal considers only the generation next, we have direct contact with them. So, direct altruistic motives are easily available in many cases. If we know that we should not worsen the present condition of the earth because it will make the living harder for my children, younger 
brothers/sisters, neighbors, and so forth, then we will feel directly motivated for altruistic actions. We can choose and have the capacity not to do anything harmful to the very next generation that is coming after because modern science and technology give us knowledge and capacity to do so. Moreover, showing respect to the idea of "leaving the earth no worse" is an easy criterion to choose, for which we have ample reasons to feel motivated. In the next section, I discuss a few such reasons for which we should care for future generations. In doing so, I also delineate how those reasons promote the idea of "leaving the earth no worse," which show that my proposal has prospects to keep the environment unharmed, and thereby it increases the probability of the continuation of human existence, on which the solution to the problem of future generations depends a lot.

\section{The Advantages of the Idea of "Leaving the Earth No Worse"}

So far, I have discussed the motivation problem which is denied by the futurists. In the last section, I have proposed a new idea which, I believe, has a good prospect to deal with this problem. Keeping that in mind, I now discuss why we ought to care for future generations in order to discern the advantages of the idea of "leaving the earth no worse."

Several arguments are given to rationalize the current generation's obligations to future generations. Wendell Bells8 mentions seven of them. Along the lines of his explanation, I show how they promote the idea of "leaving the earth no worse." They are as follows,

1. There is no clear-cut demarcation line which exists between the present and future generations.

Some members of the proximate future generations belong to current generations. Hence, " $A$ concern for present people implies a concern for future people." 39 If there is no clear demarcation line between two generations, then the reason will have graver significance to work along the line of the idea of "leaving the earth no worse." 
2. Bell40 mentions a thought experiment in which people are kept under the Rawlsian veil of ignorance. If people do not know when they will live, and if they are asked to choose the requirements of each generation, and if they do not know anything else about them, the answers they will give will show that they have a concern for both present and future generations. "Thought experiments in which choosers do not know to which generation they belong rationally imply a concern for both present and future people." 41 This thought experiment implies that under the veil of ignorance, people will also know that they should not take any measure that will harm the environment.

3. "Regarding the natural resources of the earth, present generations have no right to use to the point of depletion or to poison what they did not create." 42 No human beings created such natural resources as air, water, and soil. So, everyone has an equal share in these resources, whenever one enters the earth. The present generation should keep the shape of the earth as they found it.

4. "Past generations left many of the public goods that they created not only to the present generation but to future generations as well." 43 There are many things created by past generations, and which are now inherited by current people. But such material, social, or cultural goods are part of the human heritage. No single generation should consume them all. According to Bell, "To do the right thing, either present generations must act as stewards of their cultural heritage preserving or renewing it or they must act to replace it with works of equal or higher value." 44 No single generation is entitled to consume all the things they got from the previous generations; this implies that current generations should treat the earth as something the condition of which they cannot worsen. 
5. "Humble ignorance ought to lead present generations to act with prudence toward the wellbeing of future generations." 45 Though our knowledge has increased exponentially over the last few generations, our ignorance remains vast. Given many of our ignorance about biodiversity and bits and pieces about future generations, we should be prudent in our acts so that harm to the existence and welfare of generations to come can be avoided.

6. "There is a 'prima facie obligation of present generations to ensure that important business is not left unfinished'." 46 The important human business includes our achievements in science, art, music, literature and so on. For the continuation of these accomplishments, the continuation of human existence is required. So, if there are no future people to engage in such activities due to their struggle to live as a result of our activities threatening their existence, important human business will be left unfinished. In order to avoid such a regretful situation, we should act as a part of common humanity. As Richard A. Slaughter argues, "The limited lifespan of the individual means that all must face a personal extinction. But the knowledge of death may, to some extent, be offset by knowing that the social collectivity will continue." 47 Hence, we need to sort out those activities that are conducive to human's survival, and for it, I believe sticking to the idea of "leaving the earth no worse" has a great prospect.

7. Bell argues, following Partridge 48 , that one can attain self-enrichment and personal satisfaction through his or her concern for current and future people. Hence, “The present generation's caring and sacrificing for future generations benefits not only future generations but also itself." 49 Though it is true that present generations need to sacrifice to achieve self-enrichment and personal satisfaction, at the same time we need to keep a realistic and practical level of sacrifice. If current generations are asked to sacrifice unrealistically, it will not motivate them. 
On the contrary, they will be demoralized. Hence, it is beneficial to keep the level of sacrifice at an acceptable level, and the idea of "leaving the earth no worse" understands this reality.

From our discussion so far, it might seem to many that my concern is anthropocentric. So, in the next section, I explain why my discussion cannot be branded as a form of anthropocentrism - to be precise, as a version of strong anthropocentrism.

\section{Environmental Degradation as a Future Generations Problem}

The problem of future generations is a problem of the continuation of human existence. So, if we run any discussion in such a way that is human-centered, then it becomes anthropocentric. However, anthropocentrism may have two senses: strong and weak.50 By strong anthropocentrism, I refer to what Hayward calls "the various illegitimate ways of giving preference to human interests." 51 It is a focus that is solely concerned with "human interests to the exclusion, or at the expense, of interests of other species." 5253 I acknowledge that it is unrealistic (to some extent, impossible) to avoid any anthropocentric concern. Ignoring any anthropocentric concern at all "can be counterproductive" 54 because people will then lack positive motivations to contribute to the environment.

However, if we are solely motivated by human interests, we may create more environmental hazard than making a positive contribution to the environment. So, what can we do to minimize the risk of being exclusively anthropocentric? For that, we should include the concerns of non-human species into our consideration. Fortunately, we have ample scope to incorporate non-human species into our consideration. If we do so, strong anthropocentrism - the view that only humans are morally considerable - will turn to weak anthropocentrism - the view that nonhumans are also morally considerable, though their moral values are not as great as the values of unavoidable human interests. This sense of anthropocentrism keeps human beings still the center 
of the earth, but at the same time, it burdens us with some responsibility of considering non-humans as also morally considerable. Defining anthropocentrism in this weak sense saves it from being ecocentric that considers human beings as "part of nature" like other non-human beings for which we "have a responsibility to respect the web of life and heal the damage caused by the ideological dominance of [strong] anthropocentrism." 55 Weak anthropocentrism, on the other hand, doesn't deny our responsibility to respect the environment, but it suggests that we can respect it even by positing human beings at the center stage of nature. Weak anthropocentrism, thus, has an advantage of balancing strong anthropocentrism and ecocentrism, which is a non-anthropocentric view. As Norton points out,

Weak anthropocentrism provides a basis for criticizing individual, consumptive needs and can provide the basis for adjudicating between these levels, thereby providing an adequate basis for environmental ethics without the questionable ontological commitments made by nonanthropocentrists in attributing intrinsic value to nature.56 The strategy of a chain of love proposed by Passmore is "entirely anthropocentric, focused solely on caring for future human generations." 57 But the strategy of "leaving the earth no worse" is not completely anthropocentric. That is, the idea of chain of love favors strong anthropocentrism, whereas my idea of "leaving the earth no worse" supports weak anthropocentrism. Though the goal of leaving the earth no worse is still human-centered, the means to this end is not harmful to non-human species because when we attempt to keep the earth in the state we got from our predecessors, our actions will not be inconsiderate; we will act in the way that will not prioritize our whimsical desires with respect to the environment over the interests of non-human species that are related to their and our survival. Insofar as we leave our children a world which is no less replete with the biodiversity we found when we came to this world, we directly show care for near- 
future generations and indirectly for far future generations. In this way, the application of the strategy of "leaving the earth no worse" favors the necessary preservation of the habitat of nonhuman species. When we know that we should show care for the environment because the wellbeing of our children, younger brothers/sisters, neighbors, and so forth is dependent on the wellbeing of the environment, we are directly motivated for altruistic actions. In doing so, we can be able to preserve life-engendering conditions of human species. Thus, no unnecessary use of environment implies no environmental degradation. No environmental degradation means no biodiversity loss. No biodiversity loss entails the preservation of life-engendering conditions of human species.

Since the problem of future generations involves the problem of the human survival, and since the human's existence depends on the condition of the environment as well, any discussion of future generations involves the concern for the environment or non-human species. So, in our moral consideration, the life of non-human species should also be included. Grove-Fanning points out that "if biodiversity loss is a future generations problem, provided the criteria or moral responsibility, then moral agents are responsible to all morally considerable moral patients living in the distant future, be they human generations or other-than-human generations." 58 In this regard, respecting the idea of "leaving the earth no worse" can play a significant role. "Leaving the earth no worse" entails keeping the environment unharmed. And if we can keep the environment intact, the probability of the continuation of human existence will increase, on which the solution to the problem of future generations depends.

\section{Conclusion}

The purpose of this paper is not to propose any unrealistic model to solve the motivation problem. I understand that the motivation problem is grave. I argue that though many philosophers think 
that direct motivations are problematic for future generations only, they are not unproblematic for the current generations too, at least in some cases. In the course of discussing the indirect motives, I propose to stick to the idea of "leaving the earth no worse." In light of reasons for why we should care for future generations found in the coming generations literature, I show why such an idea should be promoted and can motivate us to work in the best interests of current and future generations. I also very briefly argue that prioritizing the idea of "leaving the earth no worse" is not exclusively anthropocentric and that acting on this idea will prevent environmental degradation that will help future generations survive for a longer period.

\section{Acknowledgement}

I am grateful to Professor Wayne Riggs, Professor Edward Sankowski and Mr. Redwan Nazim of the University of Oklahoma, and Dr. Mohammad Yousuf of the University of New Mexico for their generous comments on various drafts of this paper. I also thank an anonymous reviewer for his/her insightful and helpful comments and suggestions.

\section{Endnotes}

1 Ernest Partridge, "Introduction," in Responsibilities to Future Generations: Environmental Ethics, ed. Ernest. Partridge (Buffalo, NY: Prometheus Books, 1981), 1-20; Ernest Partridge, "Future Generations," in A Companion to Environmental Philosophy, ed. Dale Jamieson (Malden, MA: Blackwell, 2001), 377-89.

2 Norman S. Care, "Future Generations, Public Policy, and the Motivation Problem," Environmental Ethics 4.3 (1982): 195-213.

3 Partridge, "Introduction;" "Future Generations."

4 I use the terms "responsibility," "duty," and "obligation" interchangeably.

5 Partridge, "Future Generations," 377.

6 Partridge, "Introduction," 5. The phrase "morally valuable" is used in place of the phrase "value significance."

7 Ibid.

8 William Grove-Fanning, "Biodiversity Loss, the Motivation Problem, and the Future of Conservation Education in the United States" (PhD diss., University of North Texas, 2011), 23.

9 Partridge, "Future generations," 383.

10 Dieter Birnbacher, "What Motivates Us to Care for the (Distant) Future?" in Intergenerational Justice, ed. Axel Gosseries and Lukas H. Meyer (Oxford: Oxford University Press, 2009), 273-300.

11 Ibid., 278.

12 Care, "Future Generations, Public Policy," 207.

13 Ibid., 208; emphasis original.

14 Ibid.

15 Ibid.

16 Ibid., 209.

17 Ibid. 
18 Ibid., 210; emphasis added.

19 Ibid.

20 Ibid., 212.

21 Ibid., 213.

22 David Hume, An Enquiry Concerning Human Understanding, ed. Tom L. Beauchamp (Oxford: Oxford University Press, 1998).

23 Grove-Fanning, "Biodiversity Loss," 44.

24 Partridge, "Future Generations," 383-384.

${ }_{25}$ Garrett Hardin, The Limits of Altruism (Indiana: Indiana University Press, 1977).

26 Jeremy Waldron, "Who is My Neighbor?: Humanity and Proximity," The Monist 86.3 (2003): 333-354 at 340.

27 Grove-Fanning, "Biodiversity Loss," 46.

28 Birnbacher, "What Motivates Us?" 278; Grove-Fanning, "Biodiversity Loss," 46.

${ }_{29}$ Grove-Fanning, "Biodiversity Loss," 46.

30 Ibid., 63.

31 John Passmore, Man's Responsibility for Nature: Ecological Problems and Western Traditions (New York: Charles Scribner's Sons, 1974).

32 Ibid.

33 Ibid., 88.

34 Grove-Fanning, "Biodiversity Loss," 63-64.

35 Partridge, "Future Generations."

36 Ibid., 384.

37 Ibid.

38 Wendell Bell, "Why should We Care about Future Generations?" in The Years Ahead: Perils, Problems, and Promises, ed. H. F. Didsbury, Jr. (Bethesda, MD: World Future Society, 1993), 25-41.

39 Ibid., 27; emphasis original.

40 Bell, "Why should We Care?"

41 Ibid., 28; emphasis original.

42 Ibid., 29; emphasis original.

43 Ibid.; emphasis original.

44 Ibid.

45 Ibid., 31; emphasis original.

46 Bennett cited in Ibid.; emphasis original.

47 Richard A. Slaughter, "Why We should Care for Future Generations Now,” Futures 26.10 (1994): 1077-1085 at1079.

48 Ernest Partridge, "Why Care about the Future?" in Responsibilities to Future Generations: Environmental Ethics, ed. Ernest Partridge (Buffalo, NY: Prometheus Books, 1981), 203-220.

49 Bell, "Why should We Care?" 32; emphasis original.

50 Bryan G. Norton, "Environmental Ethics and Weak Anthropocentrism,” Environmental Ethics 6.2 (1984): 131-148

at 134 .

51 Tim Hayward, “Anthropocentrism: A Misunderstood Problem,” Environmental Values 6.1 (1997): $49-63$ at 52.

52 Ibid.

53 For a list of 10 ways of defining anthropocentrism essentially referring to strong or exclusive anthropocentrism, see Ben Mylius, “Three Types of Anthropocentrism,” Environmental Philosophy 15.2 (2018): 159-194 at 160-161.

54 Helen Kopnina, Haydn Washington, Bron Taylor, and John J. Piccilo, "Anthropocentrism: More than Just a Misunderstood Problem," Journal of Agricultural and Environmental Ethics 31.1 (2018): 109-127 at 109.

55 Ibid., 123.

56 Norton, "Environmental Ethics," 131.

57 Grove-Fanning, "Biodiversity Loss," 64.

58 Ibid., 24; emphasis original. 